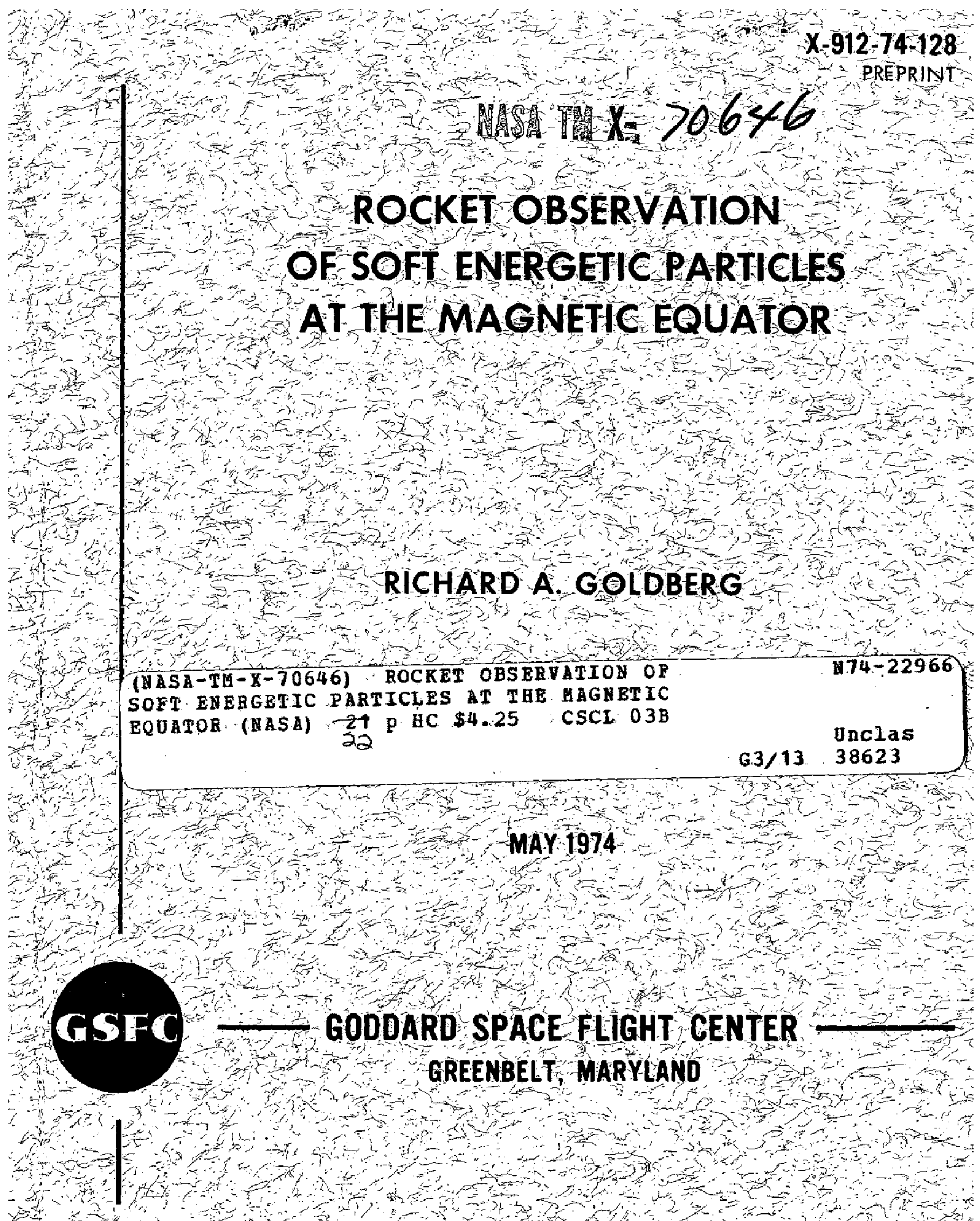




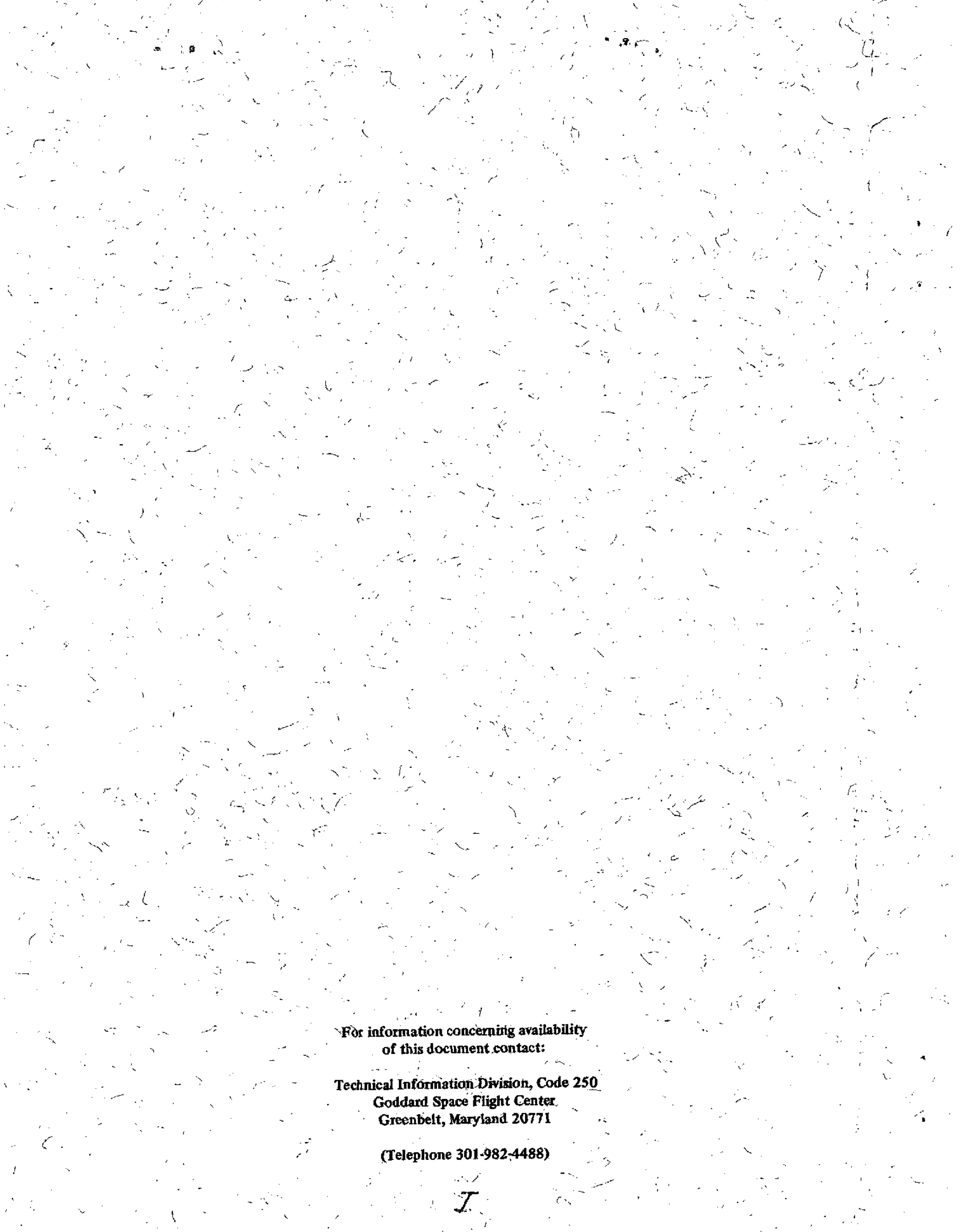


$\mathrm{X}-912-74-128$

Preprint

ROCKET OBSERVATION OF SOFT ENERGETIC

PARTICLES AT THE MAGNETIC EQUATOR

Rịchard A. Goldberg

May 1974

NASA GODDARD SPACE FLIGHT CENTER

Greenbelt, Maryland

; 


\title{
ROCKET OBSERVATION OF SOFT ENERGETIC \\ PARTICLES AT THE MAGNETIC EQUATOR
}

\author{
Richard A. Goldberg \\ NASA Goddard Space Flight Center \\ Greenbelt, Maryland 20771
}

\begin{abstract}
Results from a rocket-borne ion mass spectrometer flown near the magnetic equator at 0108 LMT, March 10, 1970, exhibit an unusual background current above $200 \mathrm{~km}$. This current is observed to increase 3.5 orders of magnitude between 200 and $260 \mathrm{~km}$ before maximizing to a fixed value from $260 \mathrm{~km}$ to the $295 \mathrm{~km}$ apogee of the flight. Properties of the background combined with laboratory measurements have permitted probable identification of the background source as 2-20 kev electrons or protons. Maximum electron fluxes have been estimated to be of the order $10^{10}$ particles $/ \mathrm{cm}^{2}-\mathrm{sec}-\mathrm{ster}$ in accord with ISIS-1 satellite measurements at higher altitudes. The background was not observed on an earlier flight at $1938 \mathrm{LMT}$, suggesting the particles to be trapped in a belt which drifted below $300 \mathrm{~km}$ between the two flights. The low altitude penetration of these fluxes may have been related to the great magnetic storm of March 8 . Simultaneous measurements of the thermal ion distribution are compared with these results and qualitatively suggest that the soft energetic particles are responsible for an observed $\mathrm{O}_{2}^{+}$and $\mathrm{NO}^{+}$enhancement.

PRECEDING PAGE BLANK NOT FILMED
\end{abstract}




\section{CONTENTS}

Page

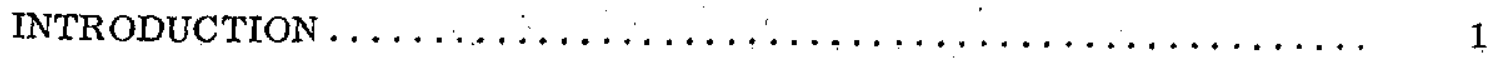

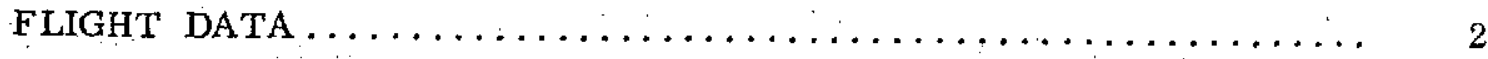

LINEAR ACCELERATOR STUDIES $\ldots \ldots \ldots \ldots \ldots \ldots \ldots \ldots \ldots \ldots$

RESULTS AND DISCUSSION $\ldots \ldots \ldots \ldots \ldots \ldots \ldots \ldots \ldots \ldots \ldots \ldots$

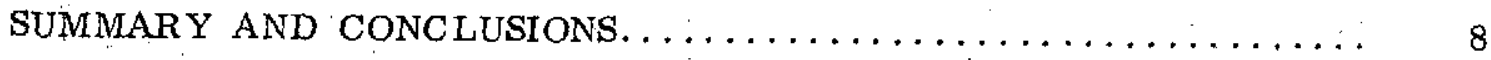

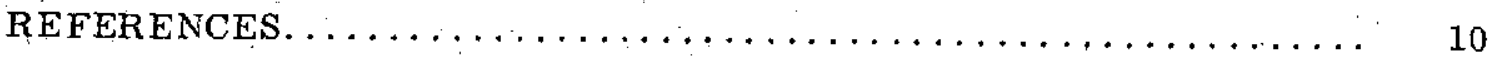

ACKNOWLEDGEMENTS $\ldots \ldots \ldots \ldots \ldots \ldots \ldots \ldots \ldots \ldots \ldots \ldots \ldots, 11$

\section{ILLUSTRATIONS}

Figure

$\underline{\text { Page }}$

1 Upleg raw spectra obtained at $197 \mathrm{~km}, 233 \mathrm{~km}$, and $291 \mathrm{~km}$ from the quadrupole ion mass spectrometer aboard NASA 18.98, launched from Thumba, India, on March 10, 1970 at 0108 LMT. A typical ac voltage sweep is also displayed....

2. Estimated particle flux with altitude calculated from the peak background current measured aboard 18.98. The arrows denote upleg and downleg portions of the flight. ...........

PRECEDING PAGE BLANK NOT FILMED 


\section{ILLUSTRATIONS (Continued)}

Figure

Page

$3 \quad$ Flight characteristics for the payload aboard 18.98:

(left) trajectory and horizontal range separation between upleg and downleg; (right) calculated dip variation along the flight

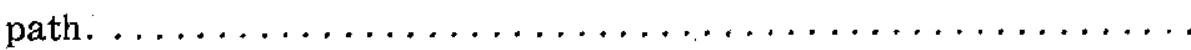

4 Laboratory calibration of flight background data. 4a (lower): slope-energy curves measured for incoming proton or electron beams produced with a linear accelerator. $I_{B 1}$ and $\mathrm{I}_{\mathrm{B} 32}$ are background currents measured at 1 amu and 32 amu, respectively. Range bars on electron data represent variation with intensity. 4b.(upper): altitude-energy relationship determined from flight data (18.98) using the calibrations in $4 \mathrm{a}$ and assuming either pure electrons or protons for the incoming radiation. $\ldots \ldots \ldots \ldots \ldots \ldots \ldots \ldots \ldots \ldots \ldots \ldots \ldots$

5 Evidence for thermal ion modification by the soft energetic particle distribution. 5a (left): peak upleg flux measured for 18.98 (cf. Figure 1). $5 \mathrm{~b}$ (center): $\mathrm{O}_{2}{ }^{+}$and $\mathrm{NO}^{+}$thermal ion distributions measured aboard both 18.97 and 18.98. The curves for each constituent have been displaced for clarity. 5c (right): electron (ion) density profiles measured aboard each rocket flight. $\ldots \ldots \ldots \ldots \ldots \ldots \ldots \ldots \ldots \ldots \ldots \ldots$ 


\section{ROCKET OBSER VATION OF SOFT ENERGETIC PARTICLES AT THE MAGNETIC EQUATOR}

\section{INTRODUCTION}

During the last decade, there have been occasional measurements in the equatorial thermosphere suggesting the presence of soft particle fluxes (low kev

range) at auroral intensities. As early as 1962, Savenko et al. (1963) estimated fluxes of $5 \times 10^{9}\left(\mathrm{~cm}^{2}-\mathrm{sec}-\mathrm{ster}\right)^{-1}$ at $320 \mathrm{~km}$ for assumed $10 \mathrm{kev}$ electrons using a satellite-borne photomultiplier detector. Most recently, Heikkila (1971) has reported similarly high fluxes for electrons, and a factor of ten less for protons, from data obtained aboard the ISIS-1 satellite with electrostatic deflection detectors. The results, obtained above $600 \mathrm{~km}$ under nighttime conditions, suggest the particles to be confined to a thermospheric altitude region under trapped conditions.

In this work, we present results from two nighttime rocket flights at the magnetic equator, which not only corroborate the satellite results from an energy-flux point of view, but lend credence to the concept of a low altitude "trapped" particle belt for soft energetic particles near the equator. These results further map the profile for this belt when at altitudes below $300 \mathrm{~km}$, well below the range limited by a perigee of $574 \mathrm{~km}$ for the ISIS-1 satellite.

The two Nike-Tomahawk payloads were launched from Thumba, India at $-1.7^{\circ} \mathrm{dip}$ (calculated from Stassinopoulos and Mead, 1972) on the night of March 9-10, 1970, at 1938 LMT (NASA 18.97) and 0108 LMT (NASA 18.98). Each payload carried a quadrupole ion mass spectrometer to an apogee near $300 \mathrm{~km}$. Further details of the instrumentation and launch characteristics are described 
in Goldberg et al. (1974). The results reported here represent the interpretation of a background current which occurred in the data of the 18.98 spectrometer, but was absent from that of the earlier flight.

\section{FLIGHT DATA}

Figure 1 illustrates three ion mass spectra obtained aboard flight 18.98 at mean altitudes of 197,233 , and $291 \mathrm{~km}$. Thermal ions were attracted with an external bias of $-10 \mathrm{v}$. The spectrometer output passed through an ITT \#FW141 multiplier with an estimated gain of approximately $2 \times 10^{5}$, prior to detection by a nearly logarithmic type electrometer. Each volt thereby represents one decade of sensitivity for the instrument. The individual peaks labelled $16^{+}, 23^{+}$, $24^{+}, 28^{+}, 30^{+}$and $32^{+}$are the ambient thermal ions $\mathrm{O}^{+}, \mathrm{Na}^{+}, \mathrm{Mg}^{+}, \mathrm{N}_{2}^{+}, \mathrm{NO}^{+}$, and $\mathrm{O}_{2}^{+}$, respectively. The constituent $18^{+}$is $\mathrm{II}_{2} \mathrm{O}^{+}$, identified as a contaminant for reasons discussed in Goldberg and Blumle (1970). The quantity $1^{+}$is not $\mathrm{H}^{+}$, but probably represents toakage from all constituents through the instrument under conditions of very weak internal electric fields. The two ledges labelled $1 \rightarrow \infty$ and $32 \rightarrow \infty$ are the cumulative currents for all ions within the designated ranges, measured while operating the instrument under high pass filter mode conditions.

The evidence for soft energetic electron or proton fluxes is contained in the background current for each spectrum. At $197 \mathrm{~km}$, the background current is close to zero and flat. By $233 \mathrm{~km}$ altitude, the background has developed a slope showing a peak value of nearly two volts at the low mass (voltage) end of the spectrometer sweep. By $291 \mathrm{~km}$, the peak background current has risen another 1.5 decades, while still exhibiting negative slope with increasing sweep 
voltage. Here, the $30^{+}$and $32^{+}$peaks are nearly masked by the excessive background current.

This effect is further studied in Figure 2, where upleg and downleg profiles are presented representing the peak background current measured for each spectrum. This current has been converted to particle flux making use of the instrumental geometric factor for straight line paths $\left(4.8 \times 10^{-6} \mathrm{~cm}^{2}\right.$-ster $)$, an estimate of the multiplication factor $\left(2 \times 10^{5}\right)$, and the assumption of $100 \%$ efficiency. A reduced yield would naturally lead to even larger flux values than those illustrated. The more likely possibility exists that the multiplier gain might have been as much as a factor of ten higher than normal, this deduced from an abnormally high sensitivity for the thermal ion data obtained on this flight. If so, the estimated flux values in Figure 2 represent an upper limit.

The downleg data exhibit a reduced value above $220 \mathrm{~km}$ which may be caused by any of several factors. Figure 3 illustrates the trajectory parameters denoting differences in horizontal range, time, and magnetic dip between up and downleg portions of the flight. Thus, at $260 \mathrm{~km}$, range difference is $30 \mathrm{~km}$, time difference is $175 \mathrm{~s}$, and dip has changed $0.55^{\circ}$. Any or all of these factors could affect the hardness and intensity of the soft particle distribution present, as discussed by Heikkila (1971) for the ISIS-1 data. The residual background flux observed below $200 \mathrm{~km}$ on the downleg portion of the flight may not be real, and in any event represents values of approximately $0.1-0.2$ volts, near the lower limit of sensitivity for the electrometer.

The payload coning angle was $\pm 4^{\circ}$, and passed through the field line perpendicular in such a manner to permit observation of the pitch angle distribution to 
$6^{\circ}$ from the field line normal. Inspection of Figure 2 shows little, if any, coning structure although the aperture half angle was only $1^{\circ}$. Hence, we have an apparent isotropic distribution within $6^{\circ}$ of the field line perpendicular, requiring the particle distribution to contain a velocity component parallel to the field line direction. J. D. Winningham (private communication) has recently established a flow parallel and downward along the field lines from ISIS-1 data, in concurrence with this result.

The possibility that the observed background effects might have been caused by instrumental factors was considered in detail and discarded. The similarity between up and downleg portions of the flight, lack of parallelism with the thermal plasma distribution (as evidenced by independent electron and ion density experiments), and difficulty in describing an instrumental malfunction capable of producing the shape and nature of the measured distribution, all support the conclusion that the origin of the observed background is indeed external. The next section describes a series of laborator y experiments designed to substantiate this conclusion.

\section{LINEAR ACCELERATOR STUDIES}

It appears that the negative slope for the spectrometer background current might be induced by increased deflection of energetic particle trajectories from straight line paths at the larger operating internal fields, as represented by the ac sweep curve in Figure 1. A larger field would increase the low energy cutoff for particle transmission, hence reducing the particle flux reaching the detector. To test this hypothesis, and to determine what type of particle distribution could be responsible for inducing the effects observed in flight, a similar 
spectrometer was bombarded with a sequence of monoenergetic particle beams generated by a linear accelerator under laboratory conditions: Both electron and proton beams were studied during this experiment.

Electrons were studied between 2 and $40 \mathrm{kev}$. The $2 \mathrm{kev}$ lower boundary represents a value just above the multiplier retarding potential. At most energies studied, the intensity of the beam was varied over several orders of magnitude to establish the effect of flux intensity on distribution shape. Protons were studied between 0.6 and $40 \mathrm{kev}$ but could not be analyzed as a function of beam intensity. The accelerator proton emission fluxes were much lower than for electrons and could only be used to determine an energy dependence.

The results of the above studies established that both electrons and protons in the 2 to $20 \mathrm{kev}$ range could induce backgr ounds of the nature observed. The results are illustrated and summarized in Figure $4 \mathrm{a}$. Here we define $\mathrm{I}_{\mathrm{B} 1}$ as the background current near mass 1 amu and $\mathrm{I}_{\mathrm{B} 32}$ as the current near mass 32 amu: The ratio $\mathrm{I}_{\mathrm{B} 1} / \mathrm{I}_{\mathrm{B} 32}$ is thus a crude measurement of the background slope and provides information concerning the energy (for monoenergetic particles) or hardness (for a spectral distribution).

The electron and proton data both clearly define a slope or curvature in the background, which increases with decreasing energy. Limits on the electron data show ranges obtained for different intensities and suggest the ratio (and hence hardness) to be independent of beam intensity. The lowest point ( $2 \mathrm{kev})$ has not been included in the estimated curve because of losses thought to be induced by the multiplier retarding potential in the spectrometer system. The range bars are absent in the proton data because of the inability to produce proton beams at multiple intensities. 
Both types of particles cause a background slope effect below $20 \mathrm{kev}$ : The proton data clearly show a larger background slope when compared to electron data at equivalent energy. Hence, a higher ratio implies more protons and/or a softer spectrum.

If the approximate calibration established in Figure $4 \mathrm{a}$ is applied to the rocket data of 18.98 , we then obtain the up and downleg energy profiles shown in Figure $4 b$, assuming either a pure distribution of protons or electrons. The energy distribution, whether representing electrons and/or protons, is clearly harder and more intense (Figure 2) during the upleg portion of the flight. This is apparent in spite of the probability that the low altitude data is in error because of possible alternate contributions (such as photons) to the background near the instrumental sensitivity limit.

Finally, we note that the linear accelerator data could not be used to calibrate and determine the flux intensity of the measured distribution during flight. Loss factors in the linear accelerator experiment were estimated to be between $10^{3}$ and $10^{6}$, caused by spectrometer misalignment and non-homogeny of the beam. Furthermore, the laboratory produced parallel beam was not typical of the isotropy deduced for the measured distribution during flight from the minimal coning effect.

\section{RESULTS AND DISCUSSION}

The night of March 9-10, 1974, was partially disturbed magnetically with Kp ranging between 4 and 6 . This permitted ionogram analysis without range spread F masking (Chandra and Rastogi, 1972) and hence, determination of the vertical drift profile for the thermal F region distribution (Goldberg et al., 1974). 
The $\mathrm{F}$ layer was found to have descended approximately $250 \mathrm{~km}$ between rocket flights 18.97 and 18.98 .

If we assume that soft energetic particles are responsive to similar drift motions under trapped or semitrapped conditions, then we can account for the absence of background current (particles) during the first flight. The particle belt simply did not penetrate to the apogee of $298 \mathrm{~km}$. The second measurement occurred following downward drift, after which the lower limit of the belt extended to approximately $200 \mathrm{~km}$. The large fluxes calculated in Figure 2 and the low altitude penetration for the particle belt may be related to effects induced by the extremely large magnetic storm of March 8, during which Kp reached values as large as 9 and Ap reached 149 .

There is some evidence that the low altitude limit for particle penetration may be defined by interaction with the neutral atmosphere. Figure 5a portrays the sharp cutoff of these particles between 250 and $200 \mathrm{~km}$ for the upleg portion or flight 18.98. Figure $5 \mathrm{~b}$ then compares the thermal ion distributions for $\mathrm{O}_{2}^{+}$ and $\mathrm{NO}^{+}$as measured on each rocket. Note here that the individual species have been displaced in the plotting procedure for clarity; the $18.98 \mathrm{O}_{2}^{+}$profile above $240 \mathrm{~km}$ actually overlaps the $\mathrm{NO}^{+}$distributions in this region. Finally, the total thermal plasmia density $\mathrm{N}_{\mathrm{e}}$ as measured with a continuous wave dispersive Doppler technique, is displayed in Figure $5 c$ to demonstrate the primary effect of drift on this distribution. It shows that above $220 \mathrm{~km}, \mathrm{O}_{2}^{+}$and $\mathrm{NO}^{+}$become minor constituents subject to an exponential decay related to the diffusive equilibrium structure of the neutral atmosphere. The total ion structure and theoretical considerations are detailed in Goldberg et al. (1974). 
Above $250 \mathrm{~km}$ and below $200 \mathrm{~km}$, the $\mathrm{O}_{2}^{+}$and $\mathrm{NO}^{+}$distributions can bể interpreted from drift and photochemical considerations. However, from 200 to $250 \mathrm{~km}$ the $10^{3} \mathrm{~cm}^{-3}$ bulge in these distributions, produced between rocket flights and especially apparent in $\mathrm{NO}^{+}$, is difficult to explain unless an additional production source occurred within this region. Qualitatively, it appears that the soft energetic particle layer could be such a source, with the lower boundary defined by atmospheric interaction and absorption. This possibility exists because of the trapped nature of the particle motion.

\section{SUMMARY AND CONCLUSIONS}

Evidence for a soft energetic particle distribution at the magnetic equator has been presented and defined from rocket-borne data. This information was retrieved from background data recorded by a multiplier detector after filtering by a quadrupole ion mass spectrometer. The interpretation of flight data was verified by laboratory controlled experiments on a similar instrument, where it was shown that 2 to $20 \mathrm{kev}$ electrons and protons would produce background structure of the type observed during flight.

Comparison of data with those of an earlier rocket flight, and with vertical drift structure determined by ionogram analysis, suggests the soft energetic particle belt to be trapped and under the influence of the same drift inducing forces governing transport of the thermal ionosphere. There is some qualitative evidence that the soft energetic particles may enhance $\mathrm{NO}^{+}$and $\mathrm{O}_{2}^{+}$concentrations near $220 \mathrm{~km}$, when drift penetration permits access to this region.

The presence of a trapped distribution for such particles near the magnetic equator, with flux intensities approaching auroral levels, is not currently 
explainable. Further experiments are necessary to establish the true nature and behavior of this distribution, and under what conditions it can achieve sufficient atmospheric penetration to influence the nighttime atmosphere and ionosphere. 


\section{REFERENCES}

Chandra, H. and R. G. Rastogi, Spread F at Magnetic Equatorial Station Thúmba, Ann. Geophys., 28, 37, 1972.

Goldberg, R. A., A. C. Aikin, and B. V. Krishna Murthy, Ion Composition and Drift Observations in the Nighttime Equatorial Ionosphere, J. Geophys. Res., 79, 1974 (in press).

Goldberg, R. A. and L. J. Blumle, Positive Ion Composition from a Rocket-Borne Mass Spectrometer, J. Geophys. Res., 75, 133, 1970.

Heikkila, W. J., Soft Particle Fluxes Near the Equator, J. Geophys. Res., 76, $1076,1971$.

Savenko, I. A., P. I. Shavrin, and N. F. Pisarenko, Soft Particle Radiation at an Altitude of $320 \mathrm{~km}$ in the Latitudes Near the Equator, Planet. Space Sci., 11, 431,1963 .

Stassinopoulos, E. G. and Gilbert D. Mead, ALLMAG, GDALMG, LINTRA: Computer Programs for Geomagnetic Field and Field Line Calculations, NSSDA 72-12, National Space Data Center, Greenbelt, Maryland, February, 1972. 


\section{ACKNOWLEDGEMENTS}

I thank Messrs. Giles Spaid, Roy Hagemeyer, Donald Silbert, Robert Farmer, and Denis Endres, all of the Chemosphere Branch, for development and preparation of the flight package, and for assistance in conducting the laboratory experiments. Mr. Stephen Brown, of the Particle Physics Branch, was responsible for providing access to the linear accelerator installation and for monitoring proper operation of the equipment involved. I am also indebted to Dr. B. V. Krishna Murthy of the Space Science and Technology Center in Trivandrum, India, for providing ionograms, and to Mr. John Jackson of the Chemosphere Branch for his invaluable assistance in ionogram interpretation, evaluation of electron density data from the $\mathrm{CW}$ propagation experiment, and detailed trajectory analysis. I also thank the staff of the Thumba Equatorial Rocket Launch Site and the Goddard Sounding Rocket Division team for their excellent cooperation and support. 


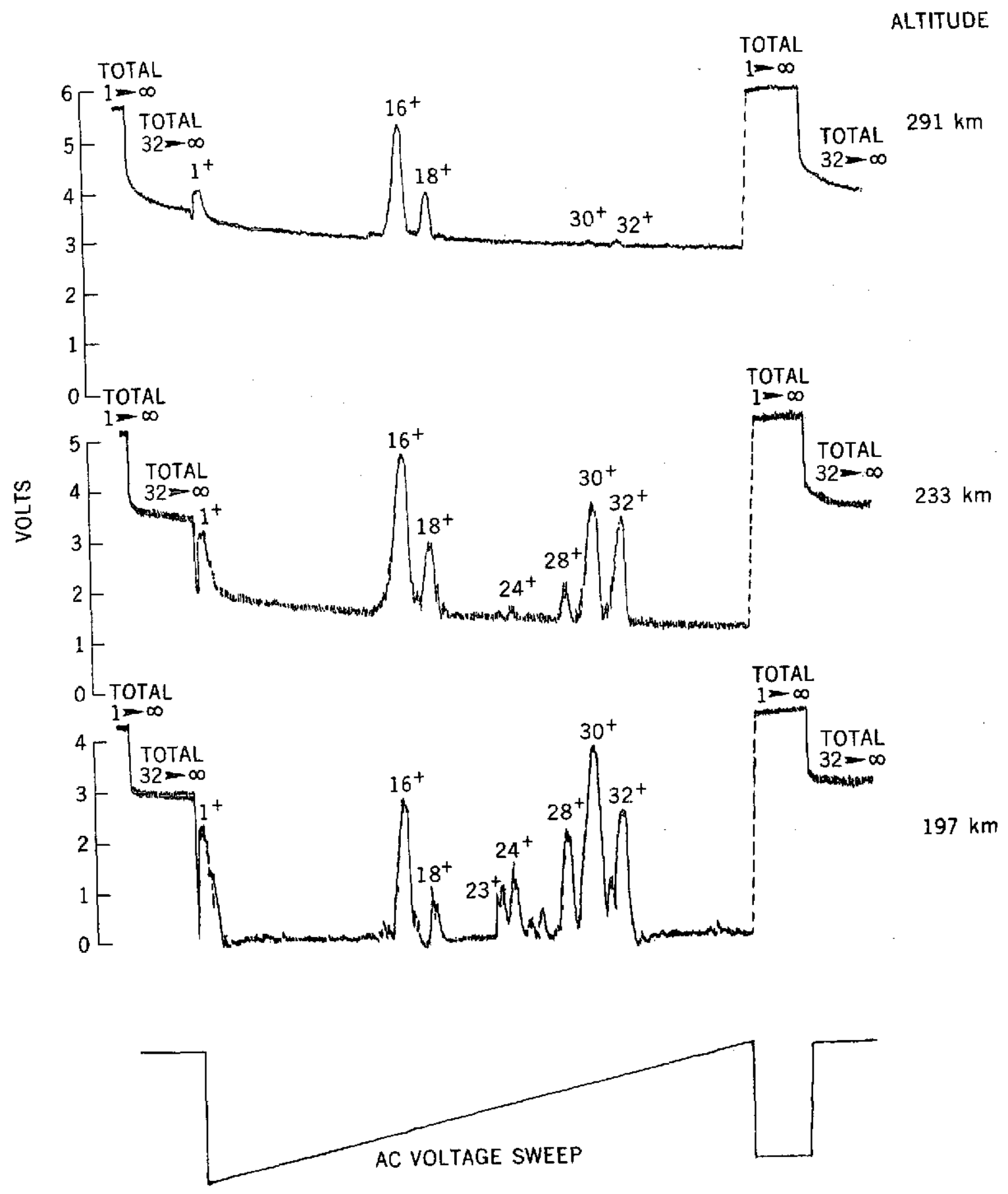

Figure 1. Upleg raw spectra obtained at $197 \mathrm{~km}, 233 \mathrm{~km}$, and $291 \mathrm{~km}$ from the quadrupole ion mass spectrometer aboard NASA 18.98 , launched from Thumba, India, on March 10, 1970 at 0108 LMT.

A typical ac voltage sweep is also displayed. 


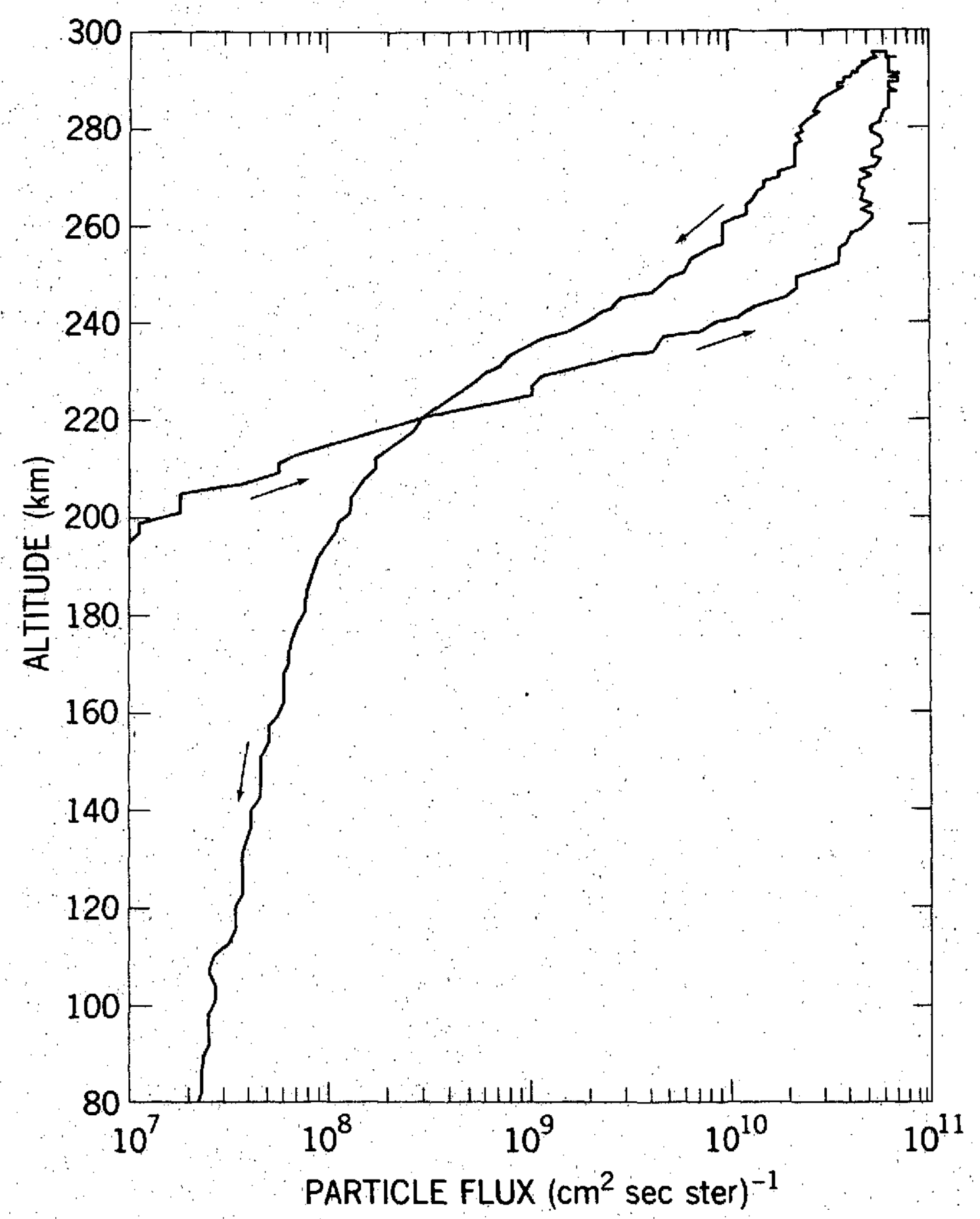

Figure 2. Estlmated particle flux with altitude calculated from the peak background current measured aboard 18.98. The arrows denote upleg and downleg portions of the flight. 

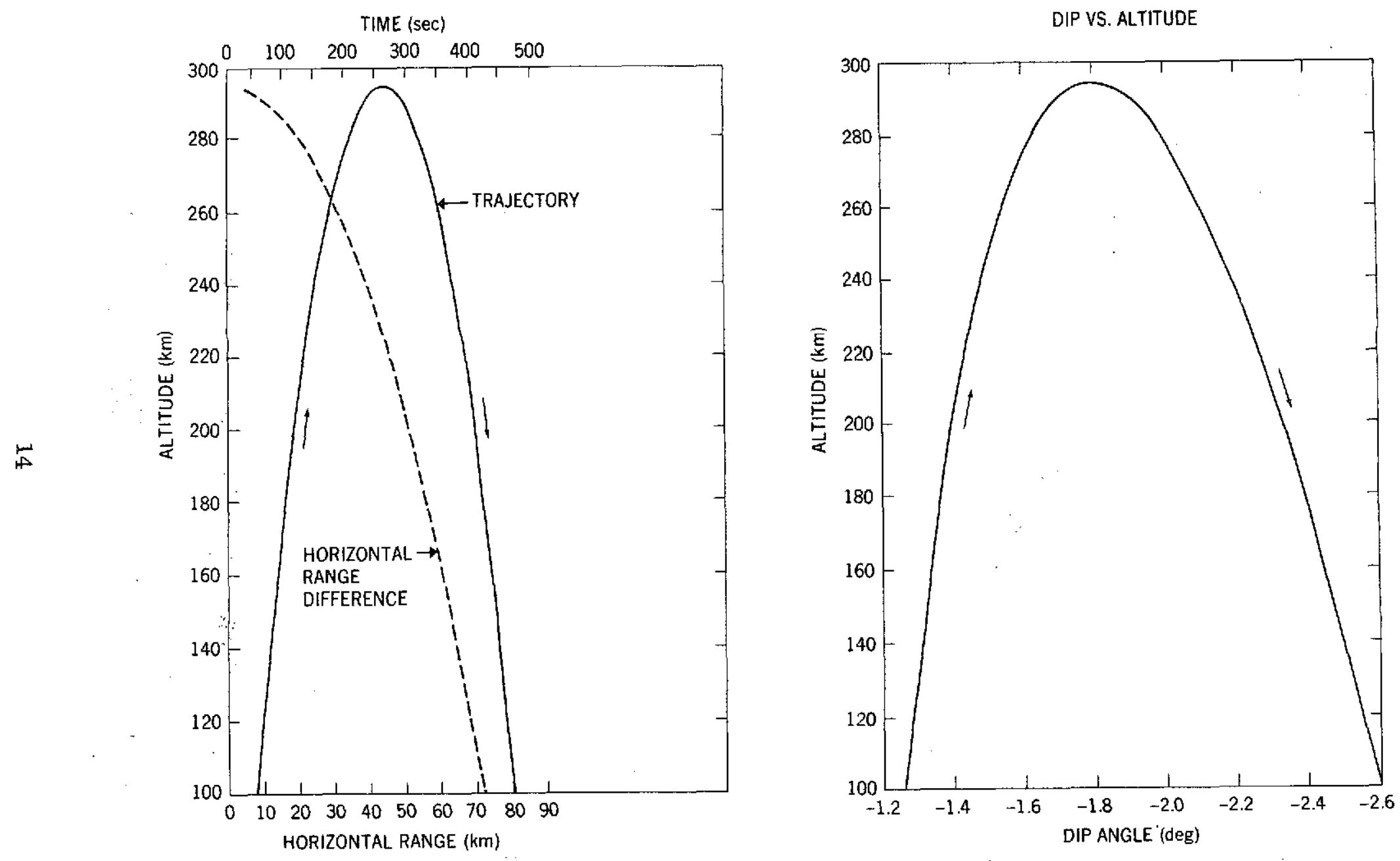

Figure 3. Flight characteristics for the payload aboard 18.98: (left) trajectory and horizontal range separation between upleg and downleg; (right) calculated dip variation along the flight path. 

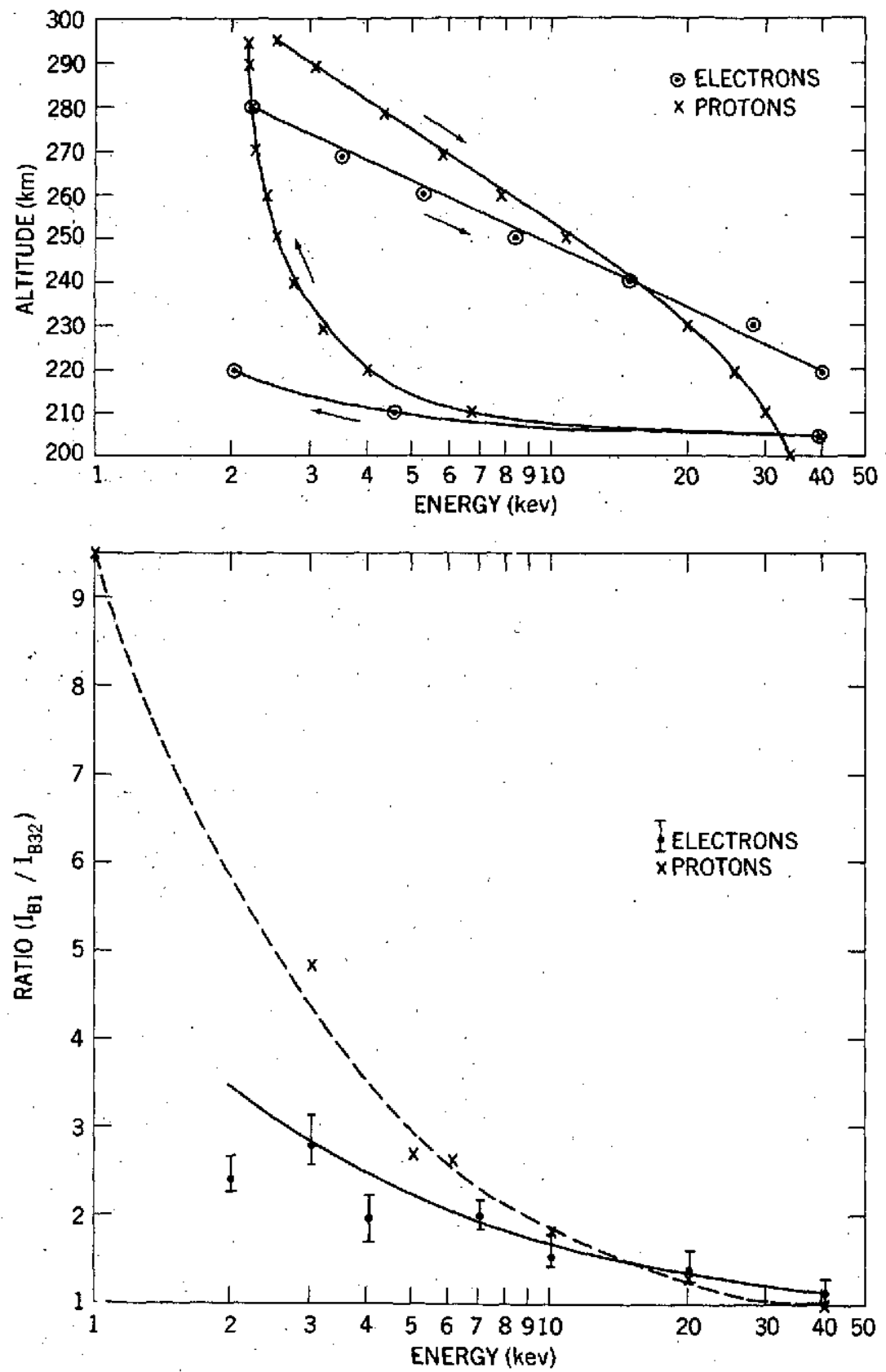

Figure 4. Laboratory calibration of flight background data. 4a (lower): slopeenergy curves measured for incoming proton or electron beams produced with

a linear accelerator. $\mathrm{I}_{\mathrm{B} 1}$ and $\mathrm{I}_{\mathrm{B} 32}$ are background currents measured at

$1 \mathrm{amu}$ and $32 \mathrm{amu}$, respectively. Range bars on electron data represent variation with intensity. 4b (upper): altitude-energy relationship determined from flight data $(18.98)$ using the calibrations in $4 a$ and assuming either pure electrons or protons for the incoming radiation. 

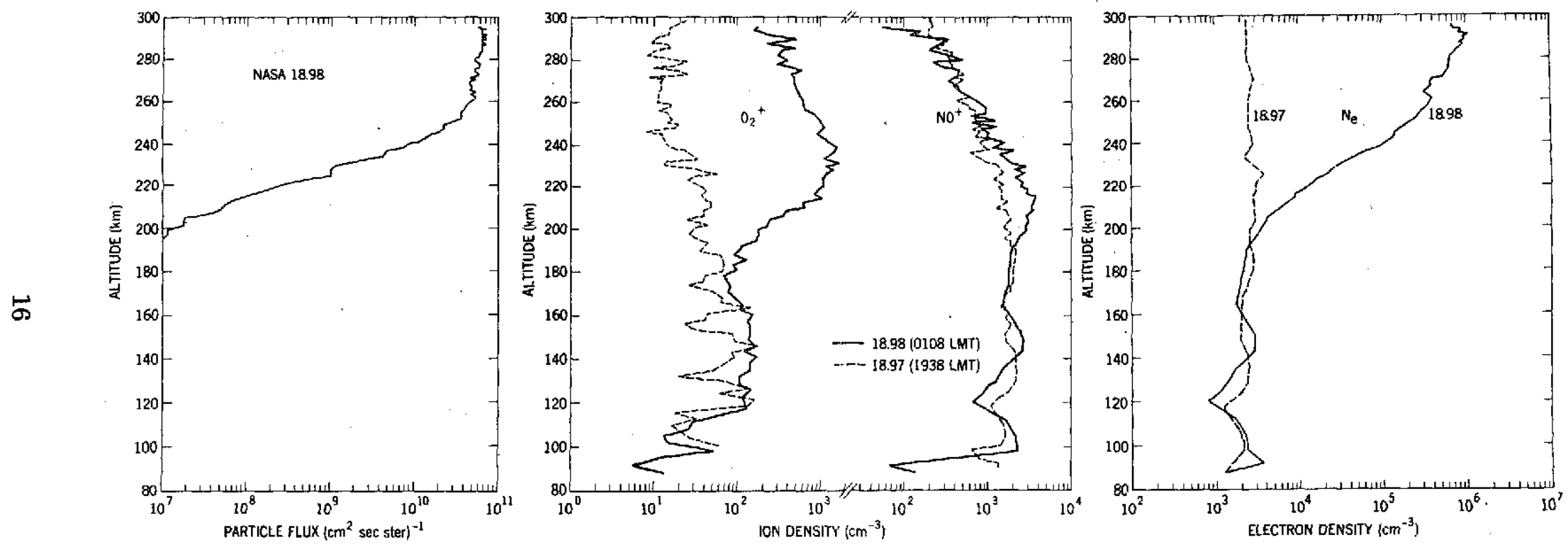

Figure 5. Evidence for thermal ion modification by the soft energetic particle distribution. 5a (left): peak upleg flux measured for 18.98 (cf. Figure 1). $5 \mathrm{~b}$ (center): $\mathrm{O}_{2}^{+}$and $\mathrm{NO}^{+}$thermal ion distributions measured aboard both 18.97 and 18.98. The curves for each constituent have been displaced for clarity. 5c (right): electron (ion) density profiles measured aboard each rocket flight. 